\title{
STABILITY OF INDEPENDENT HEAVY-DUTY SCAFFOLDS: AN EXPERIMENTAL STUDY
}

\author{
Peng, Jui-Lin ${ }^{1,}{ }^{*}$, Wang, Chung-Sheng ${ }^{2}$, Lin, Chen-Chung ${ }^{3}$ and Lin, Shu-Ken ${ }^{4}$ \\ 1 Professor, Department of Civil and Construction Engineering, \\ National Yunlin University of Science and Technology, Taiwan, China \\ 2 Ph.D. Student, Graduate School of Engineering Science and Technology, \\ National Yunlin University of Science and Technology, Taiwan, China \\ 3 Associate Researcher, Institute of Labor, Occupational Safety and Health, Ministry of Labor, \\ Executive Yuan, Taiwan, China \\ ${ }^{4}$ Lecturer, Department of Civil Engineering, National Chung Hsing University, Taiwan, China \\ *(Corresponding author: E-mail: peng.jl@msa.hinet.net) \\ Received: 7 June 2016; Revised: 27 August 2016; Accepted: 26 October 2016
}

\begin{abstract}
This study explores the stability of independent heavy-duty scaffolds by means of loading tests. The study results show that 3-story and 2-story independent heavy-duty scaffolds have very similar load capacities. The top and base screw jacks provide extra bending moment stiffness for independent heavy-duty scaffolds, which enhances the load capacity of the structural system. Horizontal braces also enhance the load capacity and the stable of independent heavy-duty scaffolds and should not be neglected. Extension of the top and base screw jacks has unobvious effect on the load capacity of independent heavy-duty scaffolds. The constructors may take advantage of this feature to adjust the height of top and base screw jacks in order to suit internal clearances and landforms of buildings. Given a similar height, as long as the number of joints is constant, the load capacities of different setups of independent heavy-duty scaffolds do not significantly vary. The eccentric load has obvious effect on the load capacity of independent heavy-duty scaffolds, which should be noted in the structure design. The age-old scaffolds treated with the red lead rust resistant paint and the used rust scaffolds have a great effect on the load capacity of the independent heavy-duty scaffolds. Therefore, they should be avoided on construction sites as much as possible. The lower limit value of the strength of reusable materials can be accurately simulated by means of the second loading in this study. Designers can choose proper strength reduction factors for reusable scaffolds based on safety requirements to conduct the structural design for independent heavy-duty scaffolds.
\end{abstract}

Keywords: Buckling, critical load, falsework, independent heavy-duty scaffold, stability

DOI: $10.18057 /$ IJASC.2017.13.4.1

\section{INTRODUCTION}

Falseworks used to construct bridges are often composed of independent heavy-duty scaffolds and traditional section steel structures. Compared to falseworks of section steel structures, independent heavy-duty scaffolds have the advantage of being easier and quicker to assemble and less restricted by the working environment. For the same area, more independent heavy-duty scaffolds are needed than the falsework of section steel structures. In construction sites with a weak geological ground condition, independent heavy-duty scaffolds have a large area of contact with the ground. Additionally, comparing with the falsework of section steel structures, uneven settlement is less likely to occur on the base of independent heavy-duty scaffolds.

For buildings with high headroom and heavy concrete weights of slabs and beams, such as gymnasiums, warehouses and high-tech plants, independent heavy-duty scaffolds are often used as falseworks. Compared to frame-type steel scaffolds, members of independent heavy-duty scaffolds have a larger diameter; there is no distinction of strong and weak axes in different setups of independent heavy-duty scaffolds; and independent heavy-duty scaffolds have a bigger load capacity. Therefore, unlike independent heavy-duty scaffolds, frame-type steel scaffolds are commonly used in reinforced concrete buildings with medium and low headroom and smaller concrete weights of labs and beams. 
Independent heavy-duty scaffolds are assembled independently as an isolated setup whereas frame-type steel scaffolds are assembled in a row-type setup. Because of their high load capacity, quick assembly and disassembly, and suitability of different working environments, independent heavy-duty scaffolds are often used in structures with heavy concrete weights of slabs and beams, such as bridges and high-tech plants. Figure 1 shows independent heavy-duty scaffolds assembled on construction sites of a high-tech plant at the Central Taiwan Science Park.

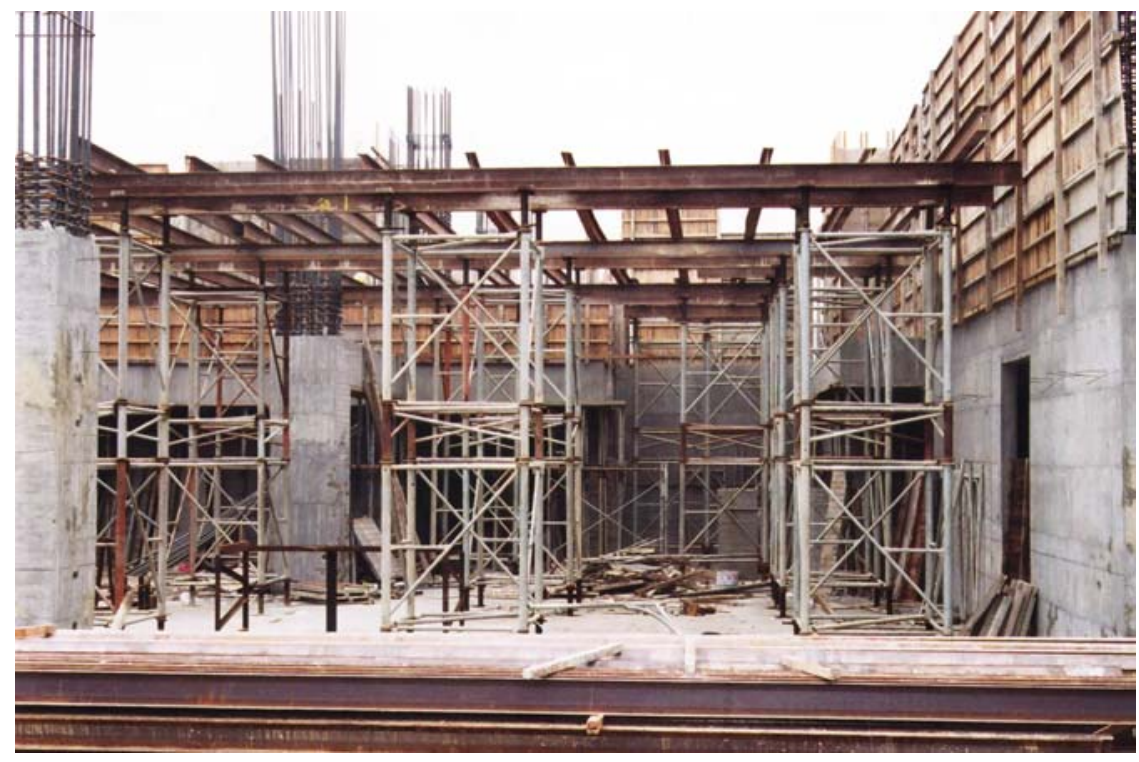

Figure 1. Independent Heavy-duty Scaffolds Assembled on Construction Sites of a High-tech Plant at the Central Taiwan Science Park

Independent heavy-duty scaffolds are widely used on construction sites in Taiwan. However, due to lack of information available for reference in design and safety assembly, independent heavy-duty scaffolds assembled on construction sites have a very high risk of collapse. Figure 2 shows the collapse scene of independent heavy-duty scaffolds on construction sites of a bridge engineering in Zhunan Section of National Freeway No. 3. The accident caused one death and two injuries on the spot.

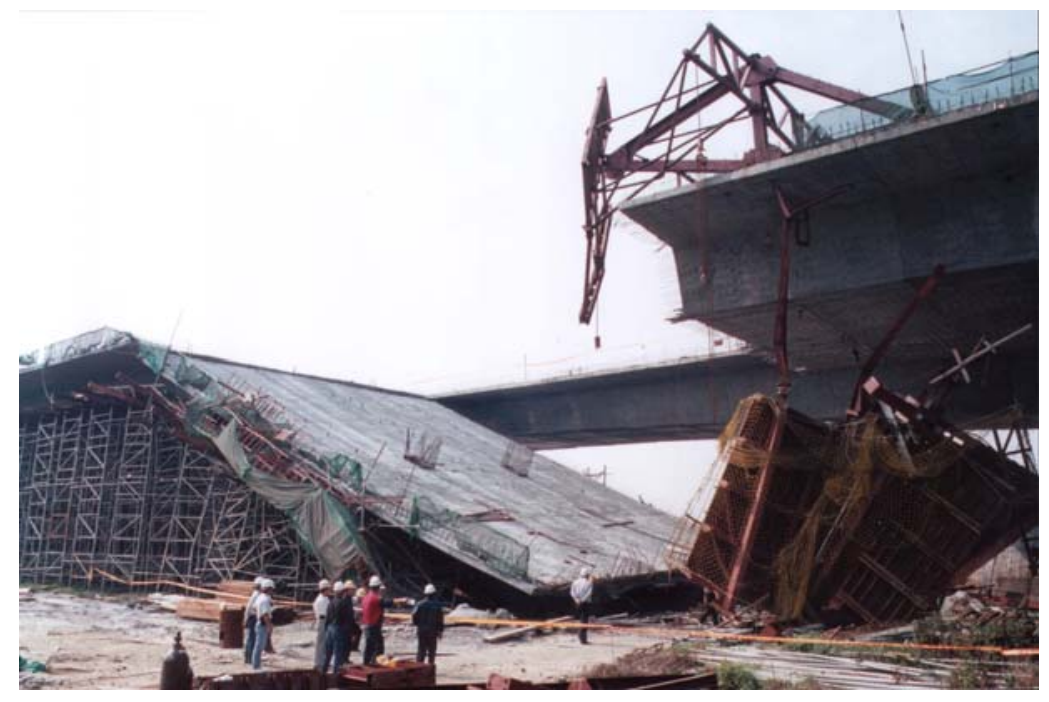

Figure 2. Collapse Scene of Independent Heavy-duty Scaffolds on Construction Sites of a Bridge in Zhunan Section of National Freeway No. 3 
Until now, most studies of falsework have focused on frame-type and door-type steel scaffolds. Apart from studying the system reliability of frame-type steel scaffolds, Zhang et al. [1] also explored the variabilities of various parameters of the load capacity of frame-type steel scaffolds.

Weesner and Jones [2] performed a numerical analysis of the strength of frame-type steel scaffolds based on eigenvalue buckling analysis and geometrically nonlinear analysis, and loading tests were conducted. Yu and Chung [3] studied the relationship between number of stories and load capacities of door-type steel scaffolds and proposed a simplified model for use in designing scaffolds. Yu et al. [4] explored the effect of different boundary conditions and X-bracing on the strength of door-type steel scaffolds.

Peng et al. [5] compared structural behaviors between "door-type steel scaffolds" and "door-type steel scaffold system with wooden shores" from the perspective of structural stability and proposed a simplified theoretical analysis model. Peng et al. [6] studied the effect of different number of stories, rows and spans on the load capacity of "door-type steel scaffolds" and "door-type steel scaffold system with wooden shores" and proposed the design guidelines for door-type steel scaffolds. Peng et al. [7] used loading tests to explore the relationship between number of spans and load capacity of single-row multi-span door-type steel scaffolds.

In terms of studies on other non-frame-type or non-door-type steel scaffolds, Peng et al. [8] studied the two-story shoring system assembled with wooden shores and adjustable steel tube shores and determined the load model and the load capacity of the two-story shoring system. Peng et al. [9] performed tests and analyses of system scaffolds to determine the load capacities and failure models in different scaffold setups. Liu et al. [10] conducted loading tests on the tube and coupler steel scaffold system without X-bracing to explore the load capacity and the failure model for the whole system. Peng et al. [11] confirmed that the critical load of the whole system decreased based on loading tests when other supporting shores were added to the top of independent heavy-duty scaffolds. Therefore, this combined setup should be avoided on construction sites.

As mentioned above, most previous studies focused on frame-type steel scaffolds, door-type steel scaffolds, tube and coupler steel scaffolds, and system scaffolds, but few on independent heavy-duty scaffolds. Unlike the above-mentioned steel scaffolds that are assembled in a row-type setup, independent heavy-duty scaffolds are assembled independently. Therefore, findings of studies on those steel scaffolds are not directly applicable to independent heavy-duty scaffolds. For this reason, the load capacity and the failure model for independent heavy-duty scaffolds need further study.

\section{OBJECTIVES AND HIGHLIGHTS}

This study analyzed the stability of independent heavy-duty scaffolds in various configurations. Loading tests are used to explore the critical load and the failure model for various independent heavy-duty scaffold setups. The results of this study are expected to serve as a reference for future structural analysis and design of independent heavy-duty scaffolds in order to reduce the risk of collapse.

This study generalizes the following key factors that affect the load capacity and the failure model for independent heavy-duty scaffolds on construction sites: (1) different number of stories, (2) without top and base screw jacks, (3) with extended top and base screw jacks, (4) without horizontal braces, (5) eccentric load, (6) with unrestrained boundary, (7) same height with different setups, (8) similar height with more joints, (9) reusable and rusted scaffolds, and (10) simulation of lower strength bounds of reusable scaffolds. Loading tests are used to explore these key factors. 


\section{SECTIONAL DIMENSIONS AND MATERIAL PROPERTIES}

Independent heavy-duty scaffolds mainly consist of triangle-type scaffold units, ledgers and horizontal braces. The triangle-type scaffold unit consists of a vertical member, a horizontal member, an internal sub-horizontal member and a diagonal brace. Figure 3 shows how various members are arranged. The figure shows that each story is composed of four triangle-type scaffold units and ledgers. Horizontal braces are placed in the junction between stories to enhance structural stability. Measurement of six setups of independent heavy-duty scaffolds obtained the average cross dimensions of various members as follows:
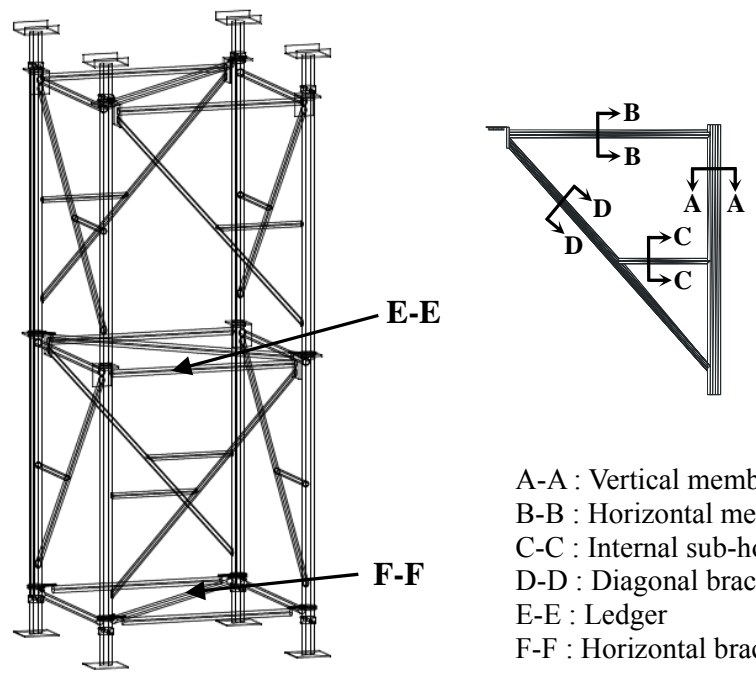

A-A : Vertical member B-B : Horizontal member C-C : Internal sub-horizontal member D-D : Diagonal brace E-E : Ledger F-F : Horizontal brace

Figure 3. Arrangement of Various Members of an Independent Heavy-duty Scaffold

In the triangle-type scaffold units: vertical member (section $A-A)$ : external diameter $(D)=76.35 \mathrm{~mm}$, thickness $(t)=3.32 \mathrm{~mm}$; horizontal member (section $B-B)$ : external diameter $(D)=42.26 \mathrm{~mm}$, thickness $(t)=2.24 \mathrm{~mm}$; internal sub-horizontal member (section $C-C$ ): external diameter $(D)=33.62$ $\mathrm{mm}$, thickness $(t)=2.24 \mathrm{~mm}$; diagonal brace (section $D-D)$ : external diameter $(D)=33.63 \mathrm{~mm}$, thickness $(t)=2.18 \mathrm{~mm}$. Ledger (section E-E): external diameter $(D)=42.35 \mathrm{~mm}$, thickness $(t)=2.40$ $\mathrm{mm}$. Horizontal brace (section F-F): external diameter $(\mathrm{D})=42.27 \mathrm{~mm}$, thickness $(\mathrm{t})=1.92 \mathrm{~mm}$.

In this study, coupon tests are performed on six sets of members randomly selected from independent heavy-duty scaffolds. The average elastic modulus (E) of the six sets of members is $20386 \mathrm{kN} / \mathrm{cm}^{2}$, which approximates the nominal value $20012.4 \mathrm{kN} / \mathrm{cm}^{2}$. Therefore, further numerical analyses can use nominal value for reference. 


\section{TEST PLAN}

\subsection{Different Number of Stories}

Different stories of independent heavy-duty scaffolds used on construction sites are needed to cope with the variation of headroom of the structure during construction. Independent heavy-duty scaffolds with different stories have different load capacities. This study performed loading tests on two-story and three-story independent heavy-duty scaffolds to explore how the load capacities of independent heavy-duty scaffolds was affected by a change in height. The test values can be used as comparing data for other tests in this study. For convenience sake, in this study, these two setups of independent heavy-duty scaffolds are defined as "basic setups". Figure 4 shows the test arrangements.

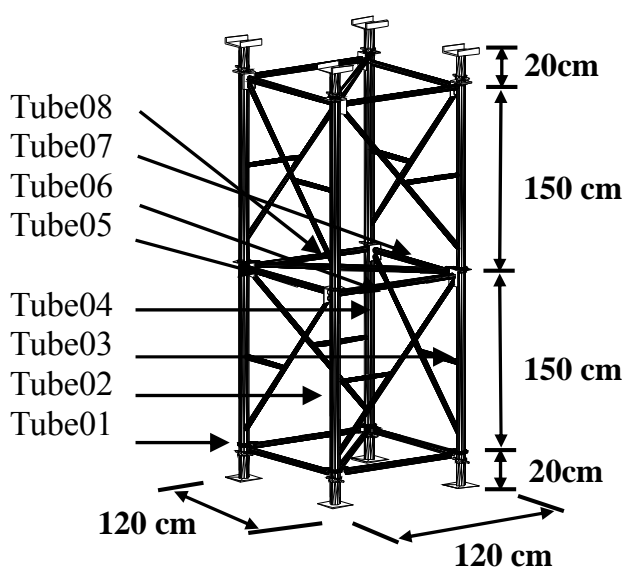

(2-story)

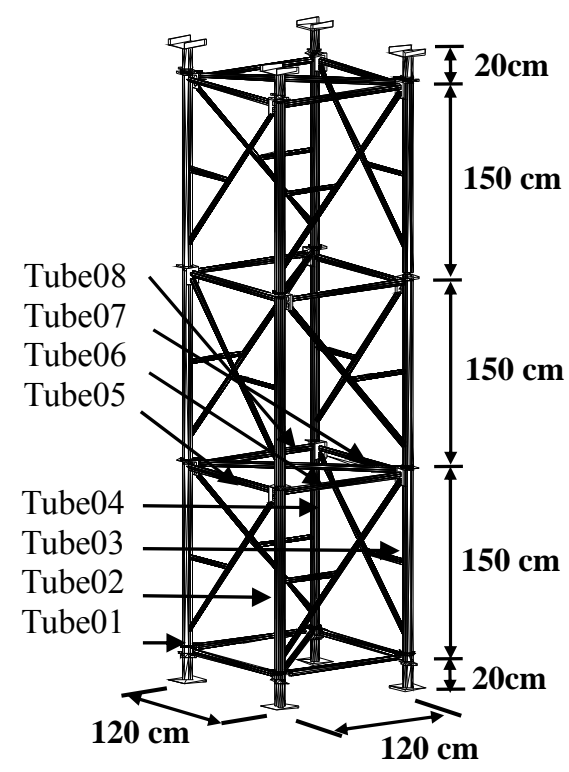

(3-story)

Figure 4. Configurations of Two-story and Three-story Independent Heavy-duty Scaffolds

This section also measures the axial forces of different members by using strain gauges attached on Tube $01 \sim$ Tube 04 for vertical members and on Tube $05 \sim$ Tube 08 for ledgers. Figure 4 shows the positions of these strain gauges in two-story and three-story independent heavy-duty scaffolds.

\subsection{Without Top and Base Screw Jacks}

The top and base screw jacks of independent heavy-duty scaffolds are mainly used to adjust the scaffold elevation. The end plates of the top and base screw jacks provide bending moment stiffness for the independent heavy-duty scaffold structural system. This study explores the effect of top and base screw jacks on the load capacity of independent heavy-duty scaffolds. The test setups are the same as those described in previous section except that the end plates of the top and base screw jacks are removed. In the numerical analysis, the boundary conditions are considered as hinged ends because no bending moment stiffness is provided due to lack of the end plates here. Figure 5 shows the test configuration of two-story independent heavy-duty scaffolds. Unless otherwise specified, the top and base screw jacks used in the tests have lengths of $20 \mathrm{~cm}$. 


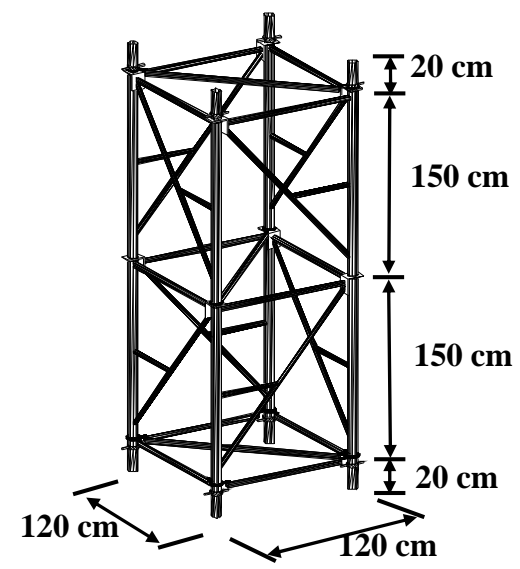

Figure 5. Configuration of Two-story Independent heavy-duty scaffolds without end plates of the top and base screw jacks

\subsection{With Extended Top and Base Screw Jacks}

On construction sites, the top and base screw jacks of independent heavy-duty scaffolds often musts be extended to cope with the variation of landforms and headrooms of structures under construction. For the tests in this study, the length of the top and base screw jacks was increased from $20 \mathrm{~cm}$ to $40 \mathrm{~cm}$ to determine the relationship between the extended length of top and base screw jacks and load capacity. Figure 6 shows the test configuration of three-story independent heavy-duty scaffolds with extended top and base screw jacks.

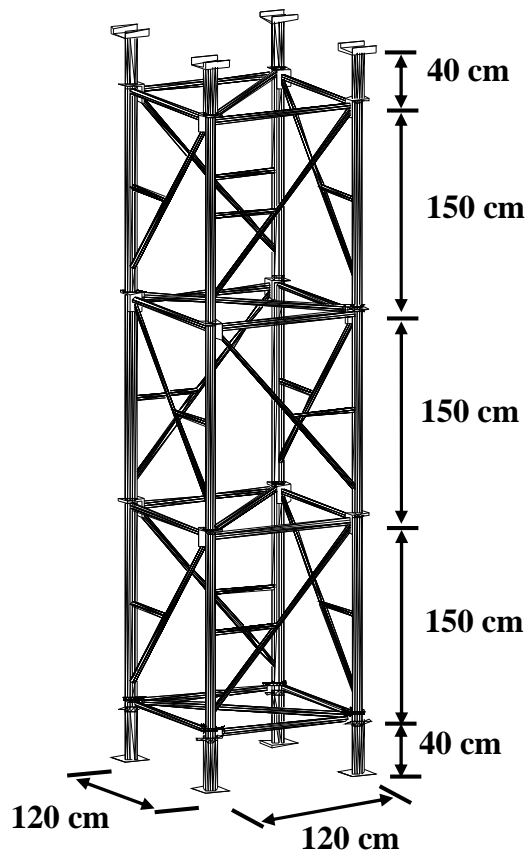

Figure 6. Configuration of Three-story Independent Heavy-duty Scaffolds with Extended Top and Base Screw Jacks 


\subsection{Without Horizontal Braces}

In the tests, the horizontal braces of independent heavy-duty scaffolds are removed to determine how the horizontal braces affect the load capacity of independent heavy-duty scaffolds. Figure 7 shows test configuration of two-story independent heavy-duty scaffolds without horizontal braces.

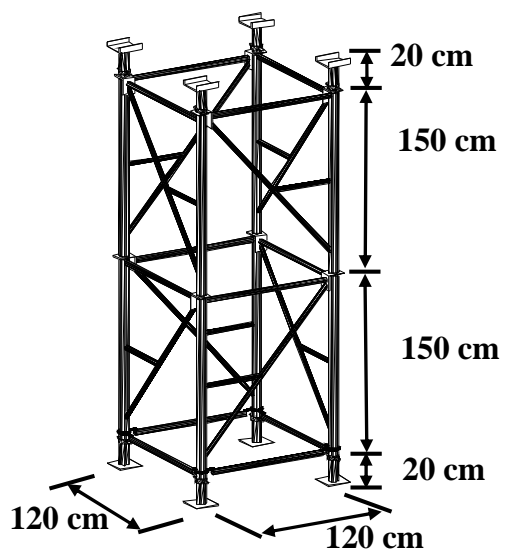

Figure 7. Configuration of Two-story Independent Heavy-duty Scaffolds without Horizontal Braces

\subsection{Eccentric Load}

On construction sites, fresh concrete is often applied following a preset grouting path. Therefore, in the process of fresh concrete grouting, the concrete load applied to independent heavy-duty scaffolds is likely to become eccentric. In the basic test setup, the load is applied eccentrically in two directions (double eccentric loading L/3). Figure 8 shows where the double eccentric loading L/3 was applied. This study explores the effect of double eccentric loading L/3 on the load capacity of independent heavy-duty scaffolds.

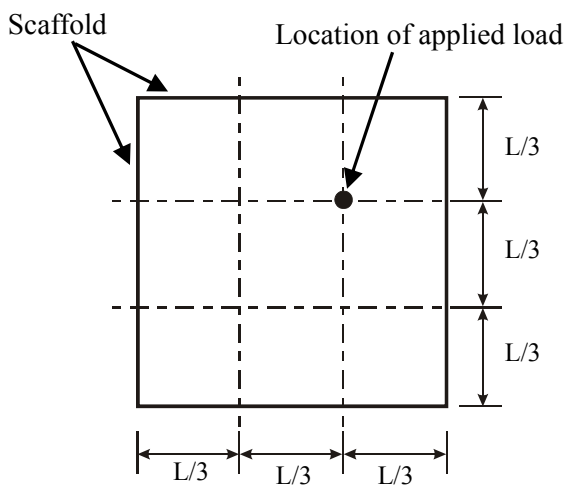

Figure 8. Top View of Location of Applied Load of Double Eccentric Loading L/3

\subsection{With Unrestrained Boundary}

On the construction site of bridge engineering, independent heavy-duty scaffolds are often assembled between two piers. No extra restraint for the bridge deck is provided in the direction perpendicular to the piers (lateral direction of the bridge). In the process of fresh concrete grouting, the bridge deck may drift laterally in the non-restraint direction, causing lateral displacement at the top of independent heavy-duty scaffolds and bridge formwork. 
Simulating lateral displacement on the top boundary of independent heavy-duty scaffolds in a universal test machine is difficult because the hydraulic jack of the universal test machine is a fixed device that does not allow lateral displacement. Therefore, the whole heavy-duty scaffold system is turned upside down to proceed the tests, turning the bottom of the system into a free end that allows lateral displacement. The free end is simulated with steel balls.

Figure 9 shows the diagram of two-story independent heavy-duty scaffolds with the possible boundary lateral displacement. Two overlapping steel plates are placed at the bottom under each vertical member in the area that touches the ground. Figure 9 shows how nine rectangular sections are divided between the two steel plates. Four steel balls are placed in each section to simulate the situation that allows boundary lateral displacement.

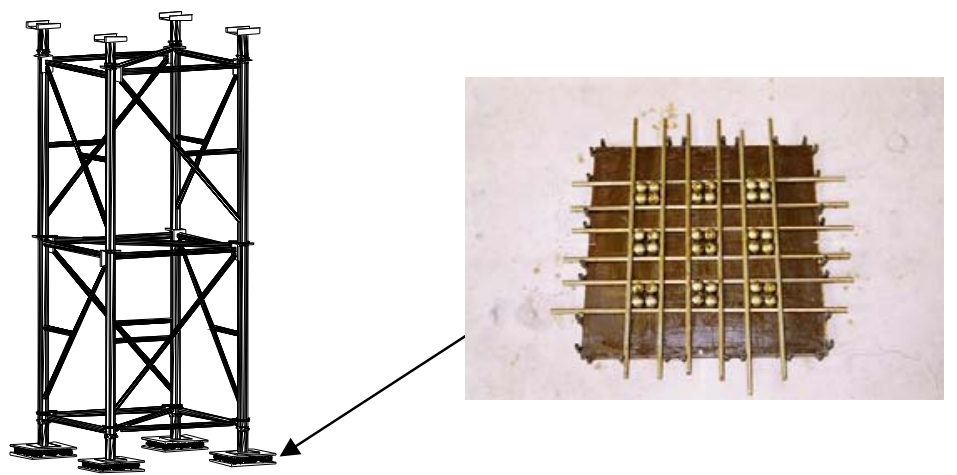

Figure 9. Configuration of Two-story Independent Heavy-duty Scaffolds with Possible Boundary Lateral Displacement

\subsection{Same Height with Different Setups}

The triangle-type scaffold unit of independent heavy-duty scaffolds is available in different sizes. With the same height, different sizes of triangle-type scaffold unit can be used to assemble independent heavy-duty scaffolds in various combinations. The objective of this study was to determine which setup has the best load capacity.

Three heights of triangle-type scaffold units are used in the tests: $0.5 \mathrm{~m}, 1 \mathrm{~m}$ and $1.5 \mathrm{~m}$. In coordination with the internal clearance of the universal test machine, the independent heavy-duty scaffolds with a total height of $3.5 \mathrm{~m}$ are used to proceed with loading tests. Tests are divided into three cases according to the heights of top, medium and bottom stories $(1.5 \mathrm{~m}, 1 \mathrm{~m}$ and $1 \mathrm{~m}$ in case A; $1.5 \mathrm{~m}, 0.5 \mathrm{~m}$ and $1.5 \mathrm{~m}$ in case $\mathrm{B} ; 1.5 \mathrm{~m}, 1.5 \mathrm{~m}$ and $0.5 \mathrm{~m}$ in case $\mathrm{C}$, respectively). Figure 10 shows the test configurations of various setups. 


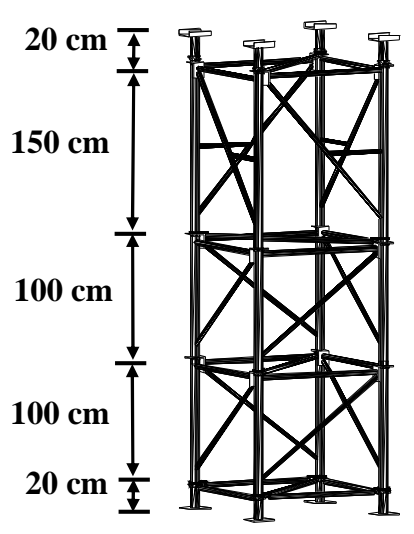

Case A $(1.5 m+1 m+1 m)$

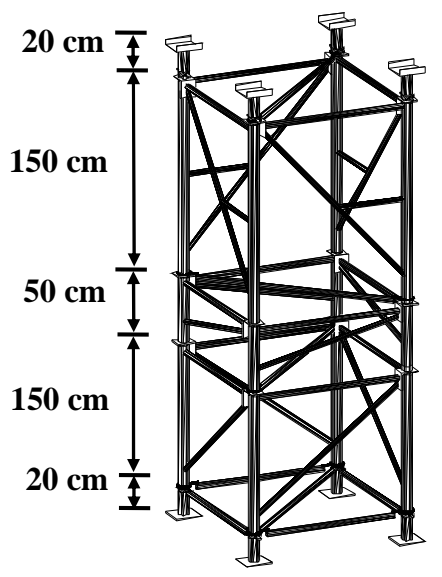

Case B (1.5m+0.5m+1.5m)

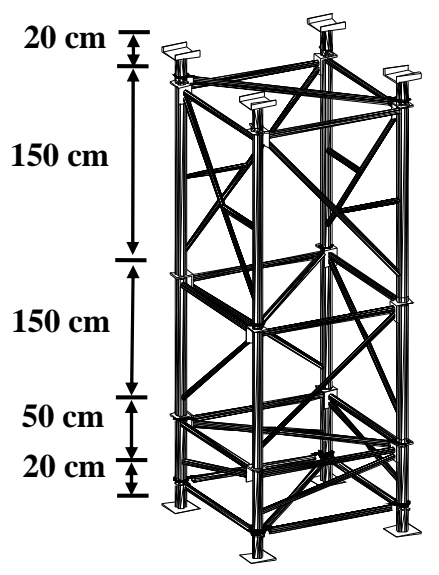

Case C (1.5m+1.5m+0.5m)

Figure 10. Configurations of Independent Heavy-duty Scaffolds with Different Sizes of Triangle-type Scaffold Units in the Same Height

\subsection{Similar Height with More Joints}

On construction sites, $150 \mathrm{~cm}$ triangle-type scaffold units are usually used to assemble independent heavy-duty scaffolds. If shorter triangle-type scaffold units, such as $110 \mathrm{~cm}$ ones, are used, there will be more joints with the same height. This study explores the variation of load capacities when there are more joints (or shorter triangle-type scaffold units are used) in the configuration of independent heavy-duty scaffolds with similar height.

In the tests, three $110 \mathrm{~cm}$ triangle-type scaffold units are used to assemble independent heavy-duty scaffolds (a three-story system with a total height of $330 \mathrm{~cm}$ ). The test results for the three-story scaffolds were compared with those for the two-story basic setup of scaffolds assembled with two $150 \mathrm{~cm}$ triangle-type scaffold units with a total height of $300 \mathrm{~cm}$. Figure 11 shows the configuration of three-story independent heavy-duty scaffolds assembled with three $110 \mathrm{~cm}$ triangle-type scaffold units with more joints compared to the two-story basic setup of scaffolds.

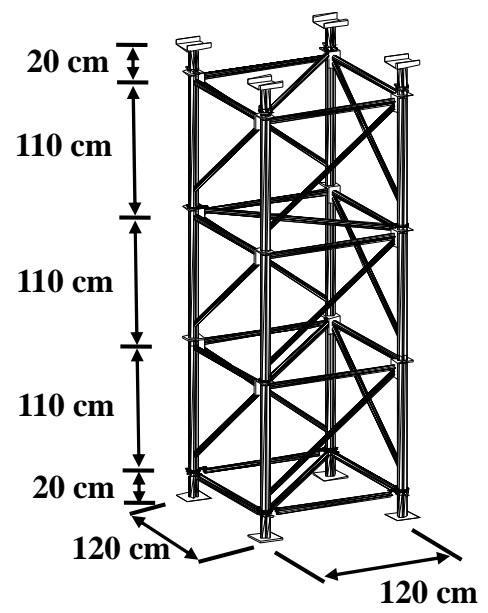

Figure 11. Configuration of Three-story Independent Heavy-duty Scaffolds Assembled with Three $110 \mathrm{~cm}$ Triangle-type Scaffold units with More Joints 


\subsection{Reusable and Rusted Scaffolds}

\section{(I) Red lead antirust paint}

Independent heavy-duty scaffolds manufactured at different times have used different antirust paint. In Taiwan, red lead antirust paint was used in early days and galvanization in more recent times for antirust treatment. This study used loading tests to explore the load capacity and failure model for independent heavy-duty scaffolds assembled with age-old and appearance defective materials treated with red lead antirust paint. The test results were then compared with those obtained from tests on the basic setup of independent heavy-duty scaffolds treated with antirust galvanizing paint.

\section{(II) Rusted used scaffolds}

Independent heavy-duty scaffolds are often reused to reduce costs. After repeated use, due to friction and collision, the antirust paint may fall off and steel tubes may be slightly sunken, which might lead to serious rustiness on independent heavy-duty scaffolds. Rust can cause the changes of material quality and tube thickness, which will reduce the load capacity of independent heavy-duty scaffolds. This study performed loading tests to explore the load capacity and failure model for independent heavy-duty scaffolds assembled with seriously rusted scaffold surfaces treated with galvanization. This test can detect the difference of load capacity between independent heavy-duty scaffolds assembled with and without severely rusted scaffold surfaces.

\subsection{Simulation of Lower Strength Bounds of Reusable Scaffolds}

This study explores the lower bounds of the load capacity of reusable independent heavy-duty scaffolds. After the first loading on independent heavy-duty scaffolds, the independent heavy-duty scaffold systems were unloaded and readjusted before the second loading. The second test values obtained will be considered the simulated lower bounds of the load capacity of reusable scaffolds. The rationale for the tests is that after the first loading, permanent deformation of the independent heavy-duty scaffolds could be used to simulate the worst condition of reusable independent heavy-duty scaffolds on construction sites.

In the tests, the strength reduction factor of reusable independent heavy-duty scaffolds $(\phi)$ was obtained by dividing the load capacity of the second loading by that of the first loading. The average of strength reduction factors $(\mu)$ and the standard deviation $(\sigma)$ can be used as a reference for the structural design of independent heavy-duty scaffolds.

\section{TEST RESULTS AND DISCUSSIONS}

\subsection{Different Number of Stories}

Table 1 shows the test results of two-story independent heavy-duty scaffolds with an average load capacity of $981.72 \mathrm{kN}$. Figure 12 is the diagram of load - vertical displacement curve (P- $\Delta$ curve) of the loading test on two-story independent heavy-duty scaffolds, which is a basic setup of independent heavy-duty scaffolds. The test results for other two-story independent heavy-duty scaffolds can be compared with those for this setup. 
Table 1. Results of Loading Tests for Various Setups of Independent Heavy-duty Scaffolds

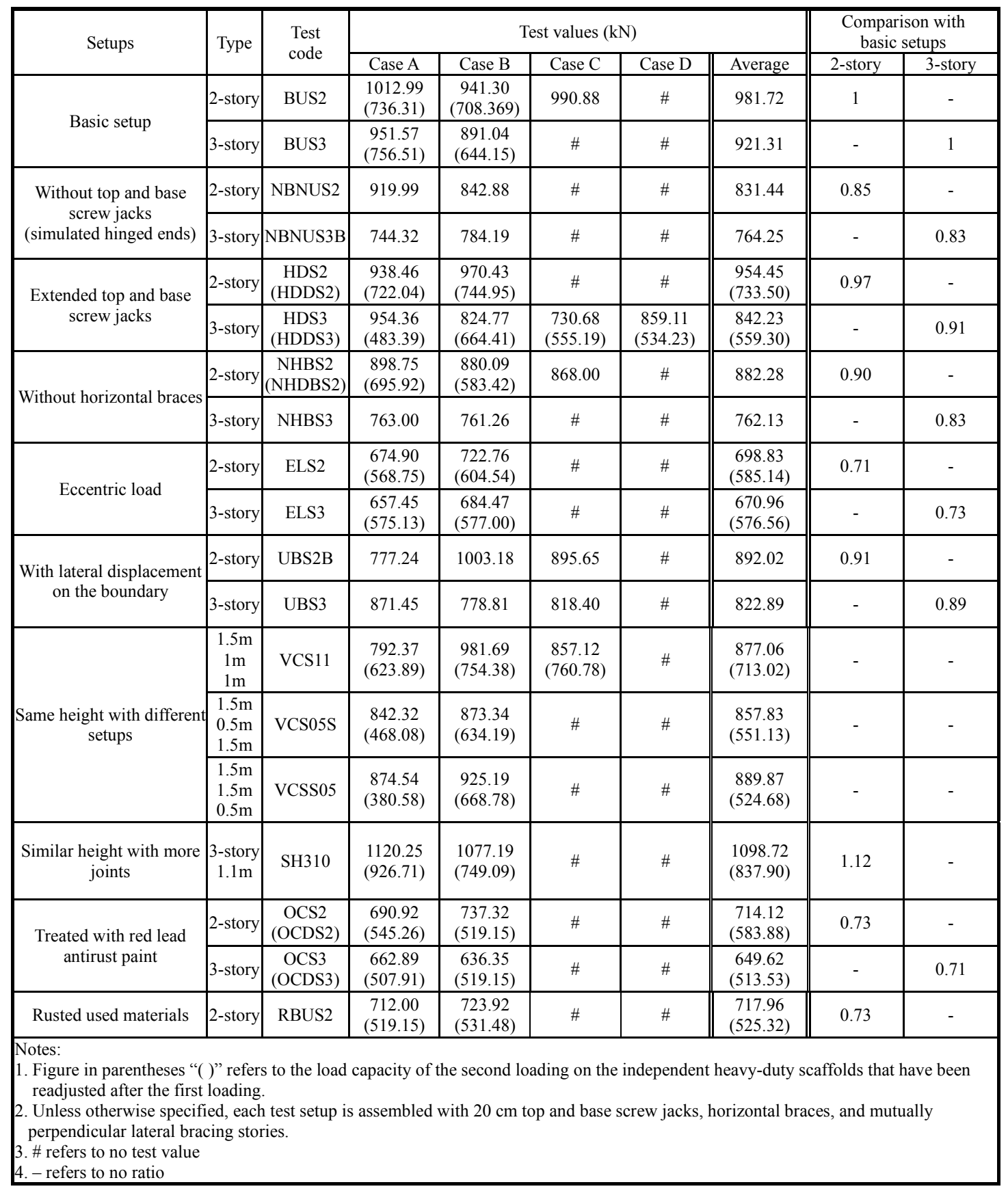

Table 1 also shows the test results of three-story independent heavy-duty scaffolds with an average load capacity of $921.31 \mathrm{kN}$. Figure 13 shows the failure model for this system under loading. By comparison, the load capacity of three-story basic setup is around 94\% (=921.31/981.72) of that of its two-story counterpart, indicating that the load capacities of these two basic setups are very close. Figures 14, 15 and 4 show the axial forces of vertical members and ledgers measured from strain gauges for two-story and three-story independent heavy-duty scaffolds. The figures show that the vertical members take most of the applied loads, and the axial forces of horizontal ledgers are insignificant. This indicates that the strong or weak vertical member influences the load capacity of independent heavy-duty scaffolds. 


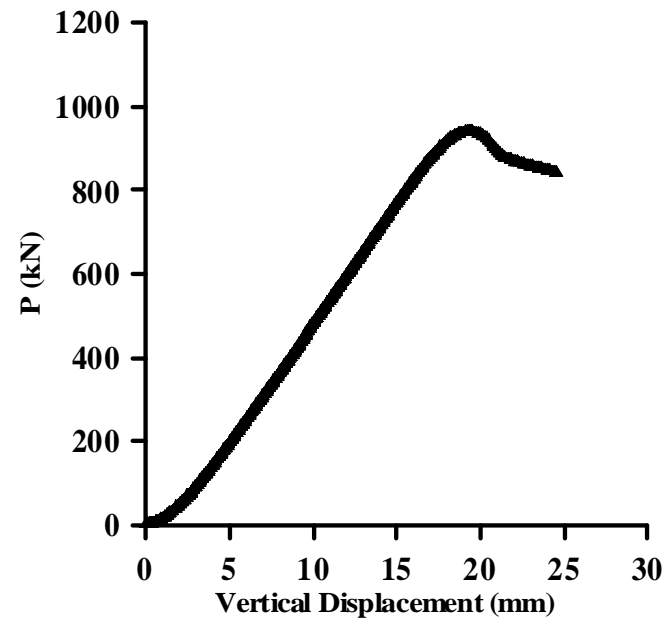

Figure 12. Load - Vertical Displacement Curve of Loading Tests on Two-story Independent heavy-duty scaffolds

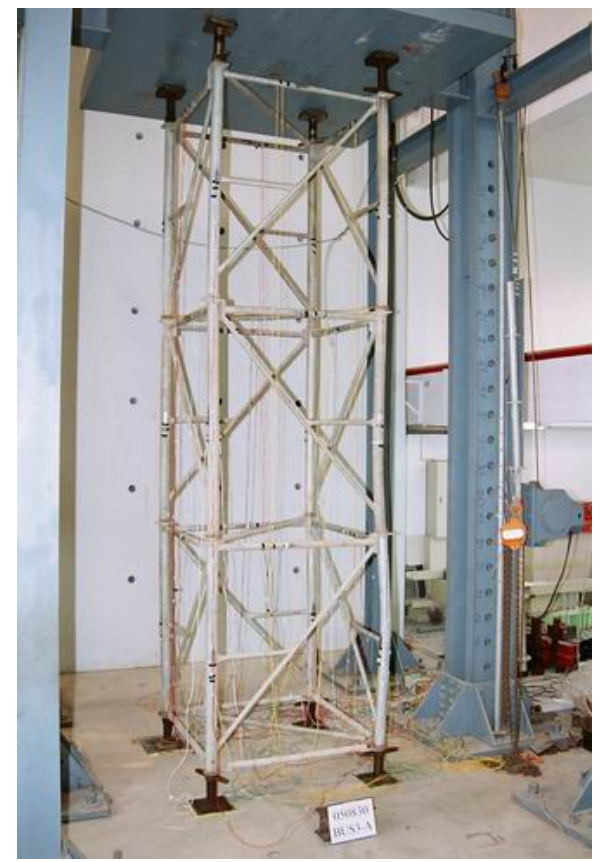

Figure 13. Failure Model for Three-story Basic Setup of Independent Heavy-duty Scaffolds under loading 


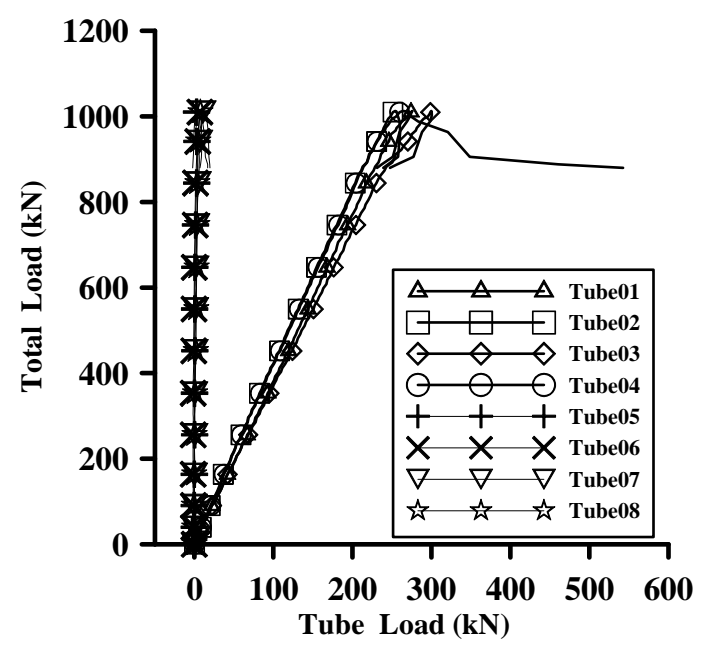

Figure 14. Total Loads-axial Forces of Vertical Members and Ledgers of

Two-story Independent Heavy-duty Scaffolds

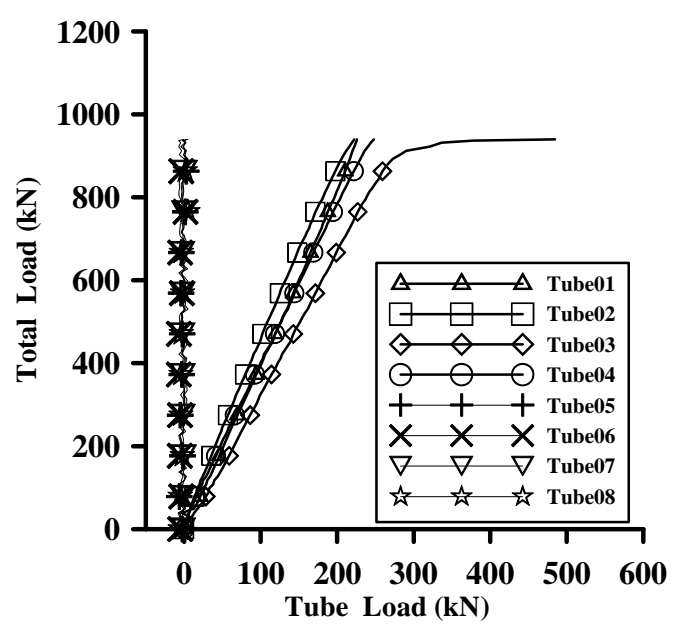

Figure 15. Total Loads-axial Forces of Vertical Members and Ledgers of Three-story Independent Heavy-duty Scaffolds

\subsection{Without Top and Base Screw Jacks}

Table 1 shows the test results of two-story and three-story independent heavy-duty scaffolds with end plates of top and base screw jacks removed to simulate hinged ends. The average load capacity of the two-story independent heavy-duty scaffolds without end plates of top and base screw jacks is $831.44 \mathrm{kN}$, which is $85 \%(=831.44 / 981.72)$ of that of the two-story basic setup. The average load capacity of three-story scaffolds without end plates is $764.25 \mathrm{kN}$, which is $83 \%$ of that in the three-story basic setup $(921.31 \mathrm{kN})$. Figure 16 shows the failure model for three-story independent heavy-duty scaffolds without end plates of top and base screw jacks under loading. The test results for the two-story and three-story independent heavy-duty scaffolds show that, because the top and base screw jacks provide bending moment stiffness, they enhance the load capacity of independent heavy-duty scaffolds. 
The quotient of the load capacity of three-story independent heavy-duty scaffolds without end plates of top and base screw jacks and that of two-story independent heavy-duty scaffolds with same conditions is $92 \%(=764.26 / 831.44)$. Therefore, the load capacity of independent heavy-duty scaffolds without end plates of top and base screw jacks, simulating hinged ends, is not significantly associated with the increase in the number of stories.

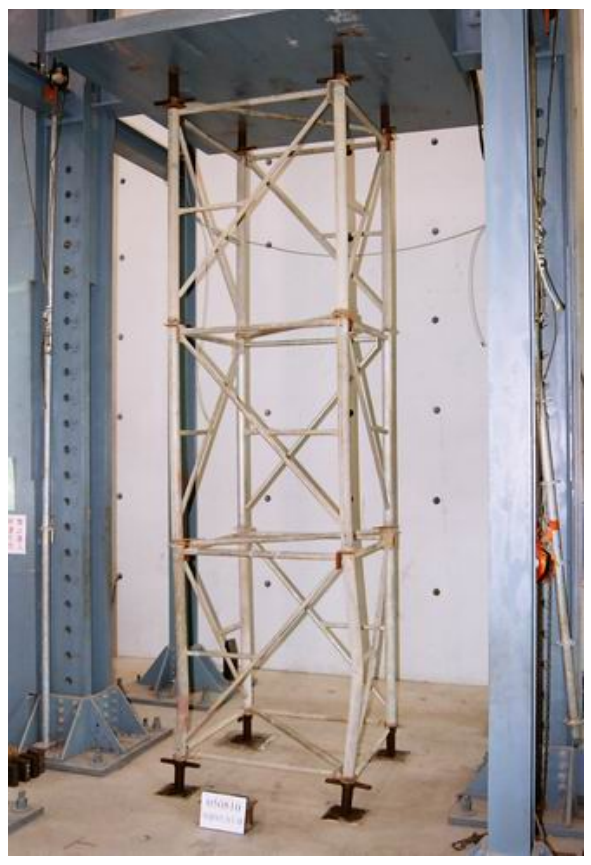

Figure 16. Failure Model for Three-story Independent Heavy-duty Scaffolds without End Plates of Top and Base Screw Jacks under Loading

\subsection{With Extended Top and Base Screw Jacks}

Table 1 shows that, when the length of top and base screw jacks is increased from $20 \mathrm{~cm}$ to $40 \mathrm{~cm}$, the average load capacity of two-story independent heavy-duty scaffolds is $954.45 \mathrm{kN}$ and that of three-story independent heavy-duty scaffolds is $842.23 \mathrm{kN}$, which are $97 \%(=954.45 / 981.72)$ and $91 \%(=842.23 / 921.31)$ of the load capacities of the two-story and three-story basic setups respectively. Figure 17 shows the failure model for three-story independent heavy-duty scaffolds with extended top and base screw jacks under loading.

The test results show that, when the top and base screw jacks of independent heavy-duty scaffolds are extended to $40 \mathrm{~cm}$, reduction of load capacity of the overall independent heavy-duty scaffold structural system is small. Based on these test results, constructors may choose to extend the length of top and base screw jacks to cope with the variation of the internal clearance of building, instead of adopting a combined setup of independent heavy-duty scaffolds, using other kinds of shores at the top of scaffolds. A combined setup reduces the load capacity of the overall scaffold system (Peng et al. 2014). 


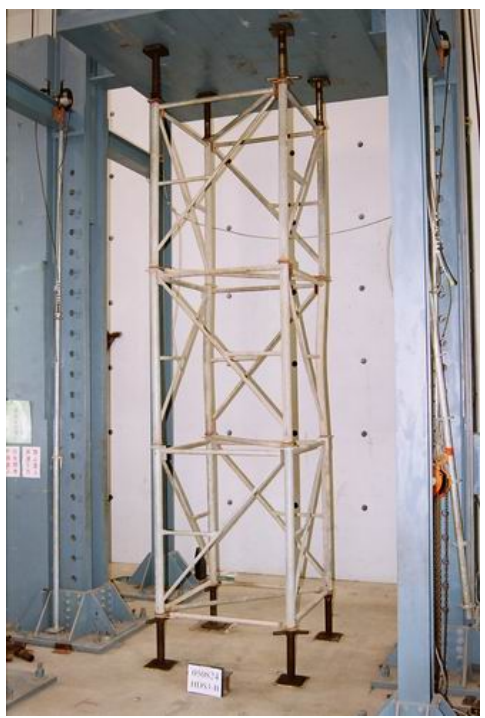

Figure 17. Failure Model for Three-story Independent Heavy-duty Scaffolds with Extended Top and Base Screw Jacks under Loading

\subsection{Without Horizontal Braces}

Table 1 shows that the average load capacity of two-story independent heavy-duty scaffolds without horizontal braces is $882.28 \mathrm{kN}$ and that of their three-story counterparts is $762.13 \mathrm{kN}$, which are $90 \%(=882.28 / 981.72)$ and $83 \%(=762.13 / 921.31)$ of the load capacities of the two-story and three-story basic setups respectively. Figure 18 shows the failure model for three-story independent heavy-duty scaffolds without horizontal braces under loading.

The test results show that the horizontal braces increase the strength of independent heavy-duty scaffolds. When independent heavy-duty scaffold systems are not reinforced with horizontal braces, with the increase of number of stories, the reduction of the load capacity of independent heavy-duty scaffold systems becomes more obvious.

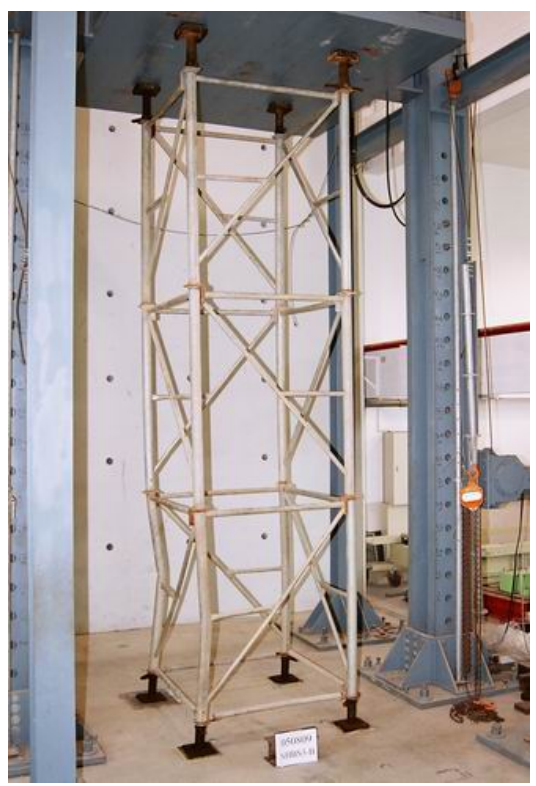

Figure 18. Failure Model for Three-story Independent Heavy-duty Scaffolds without Horizontal Braces under Loading 


\subsection{Eccentric Load}

Table 1 shows that, for the test results and Figure 8 for the setup of eccentric loading, the average load capacity of two-story independent heavy-duty scaffolds with double eccentric loading L/3 is $698.83 \mathrm{kN}$, and that of their three-story counterparts is $670.96 \mathrm{kN}$, which are $71 \%(=698.83 / 981.72)$ and $73 \%(=670.96 / 921.31)$ of the load capacities of the two-story and three-story basic setups respectively. Figure 19 shows the failure model for three-story independent heavy-duty scaffolds with double eccentric loading L/3 under loading.

The test results show that, with double eccentric loading $\mathrm{L} / 3$, the load capacity of independent heavy-duty scaffolds decreases by almost $30 \%$. Therefore, when independent heavy-duty scaffolds are used under eccentric loads, safety factors in the structural design should be increased.

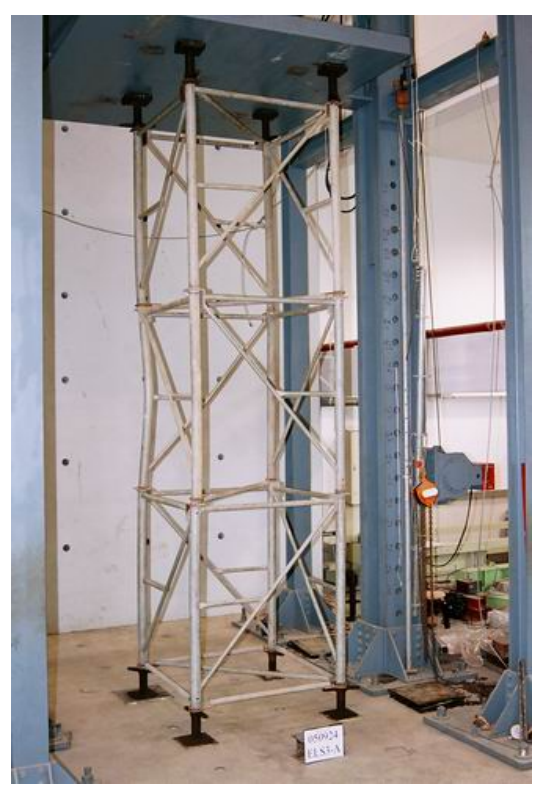

Figure 19. Failure Model for Three-story Independent Heavy-duty Scaffolds with Eccentric Load under Loading

\subsection{With Unrestrained Boundary}

Based on the unrestrained boundary in Figure 9, Table 1 shows that the average load capacity of two-story independent heavy-duty scaffolds with lateral displacement on the boundary is $892.02 \mathrm{kN}$, and that of their three-story counterparts is $822.89 \mathrm{kN}$, which are $91 \%(=892.02 / 981.72)$ and $89 \%(=822.29 / 921.31)$ of the load capacities of the two-story and three-story basic setups, respectively. Figure 20 shows the failure model for three-story independent heavy-duty scaffolds with lateral displacement on the boundary under loading.

Theoretically, a lateral displacement on the boundary significantly reduces the load capacity of independent heavy-duty scaffolds. However, the load capacity was not obviously reduced in these tests. In fact, steel balls used to simulate the roller support exist the friction force between steel plates and steel balls. The friction force $(\mathrm{F}=v \mathrm{~N})$ is proportional to the normal force $(\mathrm{N})$, where $v$ is the coefficient of friction. As the applied load from the universal test machine increases, the friction force rises with the increase of the normal force. As the friction force was increased in the tests, the lateral displacement on the boundary became unobvious so that the reduction of load capacity of the independent heavy-duty scaffolds was not as high as expected. 


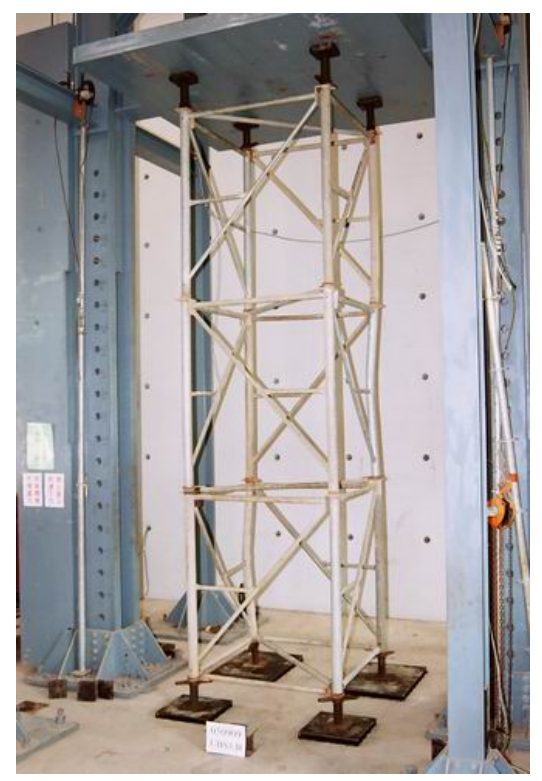

Figure 20. Failure Model for Three-story Independent Heavy-duty Scaffolds with Lateral Displacement on the Boundary under Loading

\subsection{Same Height with Different Setups}

Figure 10 shows that the three setups of independent heavy-duty scaffolds were considered in the tests - Cases A, B and C. Table 1 shows the test results, which revealed that the average load capacity of case A (the heights of top, medium and bottom stories are $1.5 \mathrm{~m}, 1 \mathrm{~m}$ and $1 \mathrm{~m}$ respectively) is $877.06 \mathrm{kN}$; the average load capacity of case $\mathrm{B}$ (the heights of top, medium and bottom stories are $1.5 \mathrm{~m}, 0.5 \mathrm{~m}$ and $1.5 \mathrm{~m}$ respectively) is $857.83 \mathrm{kN}$; the average load capacity of case $\mathrm{C}$ (the heights of top, medium and bottom stories are $1.5 \mathrm{~m}, 1.5 \mathrm{~m}$ and $0.5 \mathrm{~m}$ respectively) is $889.87 \mathrm{kN}$. Figure 21 shows the failure models for three cases of independent heavy-duty scaffolds. The test results show that, for a height of $3.5 \mathrm{~m}$, although case $\mathrm{C}$ has the highest load capacity, the load capacities of cases A and B do not lag far behind case $\mathrm{C}$, indicating that when the height is the same, the load capacities of independent heavy-duty scaffolds assembled with different sizes of triangle-type scaffold units are similar.

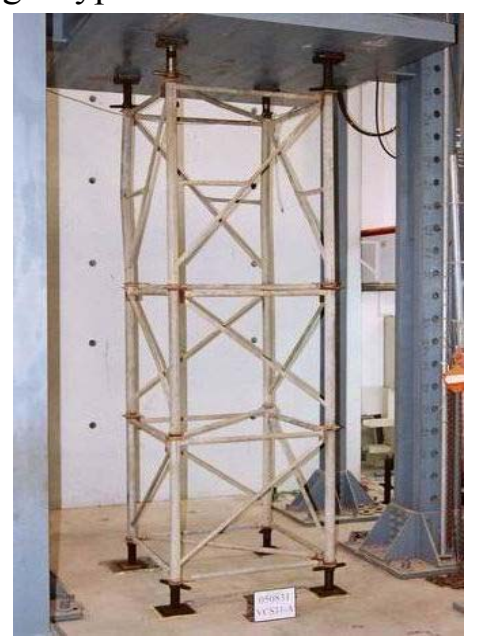

Case A $(1.5 \mathrm{~m}+1 \mathrm{~m}+1 \mathrm{~m})$

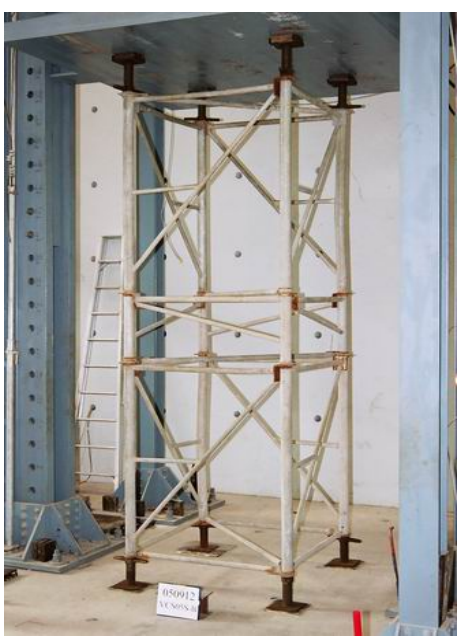

Case B $(1.5 \mathrm{~m}+0.5 \mathrm{~m}+1.5 \mathrm{~m})$

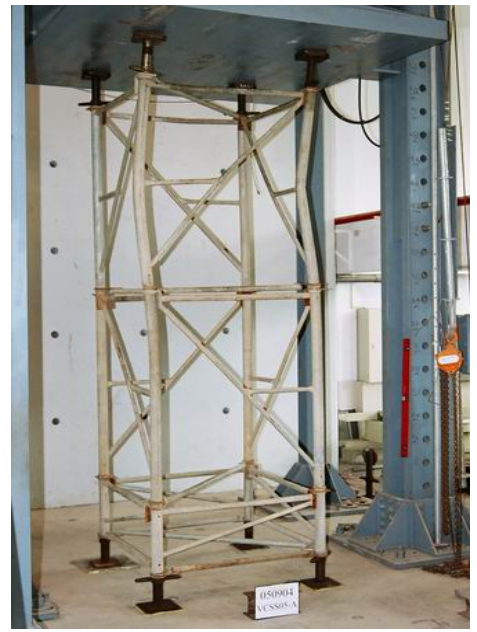

Case C $(1.5 \mathrm{~m}+1.5 \mathrm{~m}+0.5 \mathrm{~m})$

Figure 21. Failure Models for Independent Heavy-duty Scaffolds with the Same Height but Different Configurations 


\subsection{Similar height with more joints}

As shown in Table 1, the average load capacity of three-story independent heavy-duty scaffolds assembled with three $110 \mathrm{~cm}$ triangle-type scaffold units (total height $=330 \mathrm{~cm}$ ) is $1098.72 \mathrm{kN}$. Figure 22 shows the failure model for this structural system. The average load capacity of two-story independent heavy-duty scaffolds assembled with two $150 \mathrm{~cm}$ triangle-type scaffold units (total height $=300 \mathrm{~cm})$ is $981.72 \mathrm{kN}$. The quotient of the former $(1098.72 \mathrm{kN})$ divided by the latter $(981.72 \mathrm{kN})$ is $112.0 \%$. The test results show that, for a total height circa $300 \mathrm{~cm}$, independent heavy-duty scaffolds assembled with shorter triangle-type scaffold units have a higher total height and more joints but a higher load capacity.

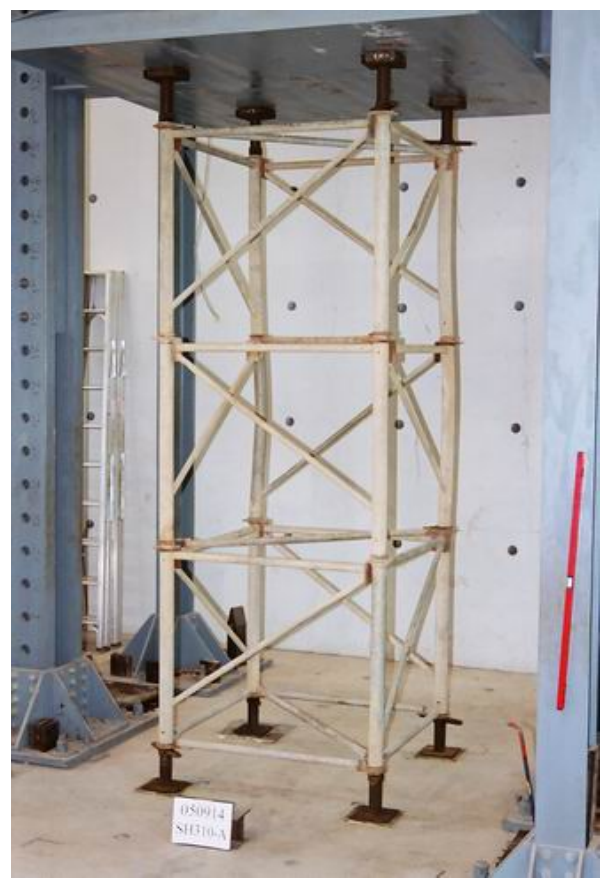

Figure 22. Failure Model for Three-story Independent Heavy-duty Scaffolds Assembled with Three $110 \mathrm{~cm}$ Triangle-type Scaffold Units under Loading (total height $=330 \mathrm{~cm}$ )

\subsection{Reusable and Rusted Scaffolds}

\section{(I) Red lead antirust paint}

As shown in Table 1, the average load capacities of two-story and three-story reusable independent heavy-duty scaffolds treated with red lead antirust paint are $714.12 \mathrm{kN}$ and $649.62 \mathrm{kN}$ respectively, which are $73 \%(=714.12 / 981.72)$ and $71 \%(=649.62 / 921.31)$ of the load capacities of two-story and three story basic setups respectively. Figure 23 shows the failure model for three-story reusable independent heavy-duty scaffolds treated with red lead antirust paint under loading. 


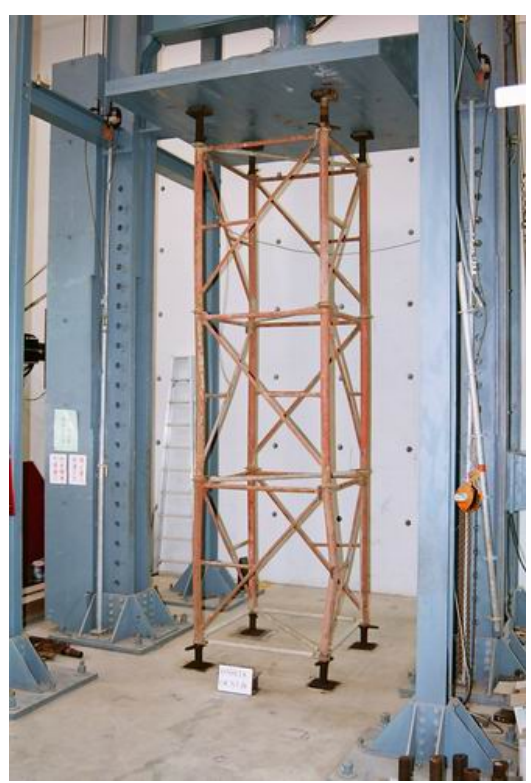

Figure 23. Failure Model for Three-story Reusable Independent Heavy-duty Scaffolds Treated with Red Lead Antirust Paint under Loading

\section{(II) Rusted used Scaffolds}

In this case, the tests were mainly performed on two-story independent heavy-duty scaffolds. The load capacity of two-story reusable and rusted independent heavy-duty scaffolds is $717.96 \mathrm{kN}$, which is 73\% (=719.96/981.72) of two-story basic setup. Therefore, using reusable and rusted independent heavy-duty scaffolds has a large effect on load capacity.

As shown by the test results, the load capacity of independent heavy-duty scaffolds assembled with aged materials treated with red lead antirust paint or rusted used materials reduces around $30 \%$. Therefore, on construction sites, when assembling independent heavy-duty scaffolds, constructors should avoid using age-old or rusted used materials in order to enhance the construction safety.

\subsection{Simulation of Lower Strength Bounds of Reusable Scaffolds}

According to the tests, the deformation of independent heavy-duty scaffolds after the first loading is the worst condition of the reusable scaffolds on construction sites. The load capacity of the second loading is defined as the "simulation of lower strength bounds of reusable scaffolds". The strength reduction factor of load capacity of the reusable independent heavy-duty scaffolds $(\phi)$ is obtained by dividing the load capacity of the second loading by that of the first loading. 
Table 2. Simulated Lower Strength Bounds of Load Capacities of the Reusable Independent heavy-duty scaffolds

\begin{tabular}{|c|c|c|c|c|c|c|c|}
\hline \multirow[b]{2}{*}{ Setup } & \multirow[b]{2}{*}{ Type } & \multirow[b]{2}{*}{$\begin{array}{l}\text { Test } \\
\text { case }\end{array}$} & \multicolumn{2}{|c|}{$\begin{array}{l}\text { Average test values } \\
(\mathrm{kN})\end{array}$} & \multirow{2}{*}{$\begin{array}{r}=2^{\text {nd }} \\
\text { loading } / 1^{\mathrm{s}} \\
{ }^{t} \text { loading }\end{array}$} & \multirow[b]{2}{*}{ Average } & \multirow[b]{2}{*}{$\begin{array}{l}\text { Standard } \\
\text { deviation }\end{array}$} \\
\hline & & & $\begin{array}{l}1^{\text {st }} \text { loading } \\
\text { Load } \\
\text { capacity }\end{array}$ & $\begin{array}{l}2^{\text {nd }} \text { loading } \\
\text { Load } \\
\text { capacity }\end{array}$ & & & \\
\hline \multirow{4}{*}{ Basic setup } & \multirow{2}{*}{ 2-story } & $\mathrm{A}$ & 1012.99 & 736.31 & 0.727 & \multirow{25}{*}{0.739} & \multirow{25}{*}{0.111} \\
\hline & & $\mathrm{B}$ & 941.3 & 708.369 & 0.753 & & \\
\hline & \multirow{2}{*}{ 3-story } & $\mathrm{A}$ & 951.57 & 756.51 & 0.795 & & \\
\hline & & $\mathrm{B}$ & 891.04 & 644.15 & 0.723 & & \\
\hline \multirow{2}{*}{$\begin{array}{l}\text { Without } \\
\text { horizontal } \\
\text { brace }\end{array}$} & \multirow[b]{2}{*}{ 2-story } & $\mathrm{A}$ & 898.75 & 695.92 & 0.774 & & \\
\hline & & B & 880.09 & 583.42 & 0.663 & & \\
\hline \multirow{6}{*}{$\begin{array}{l}\text { Extended } \\
\text { top/base } \\
\text { screw jacks }\end{array}$} & \multirow{2}{*}{ 2-story } & $\mathrm{A}$ & 938.46 & 722.04 & 0.769 & & \\
\hline & & $\mathrm{B}$ & 970.43 & 744.95 & 0.768 & & \\
\hline & \multirow{4}{*}{ 3-story } & $\mathrm{A}$ & 954.36 & 483.39 & 0.507 & & \\
\hline & & $\mathrm{B}$ & 824.77 & 664.41 & 0.806 & & \\
\hline & & $\mathrm{C}$ & 730.68 & 555.19 & 0.760 & & \\
\hline & & $\mathrm{D}$ & 859.11 & 534.23 & 0.622 & & \\
\hline \multirow{4}{*}{ Eccentric load } & \multirow{2}{*}{ 2-story } & $\mathrm{A}$ & 674.90 & 568.75 & 0.843 & & \\
\hline & & $\mathrm{B}$ & 722.76 & 604.54 & 0.836 & & \\
\hline & \multirow{2}{*}{3 -story } & $\mathrm{A}$ & 657.45 & 575.13 & 0.875 & & \\
\hline & & $\mathrm{B}$ & 684.47 & 577.00 & 0.843 & & \\
\hline \multirow{7}{*}{$\begin{array}{l}\text { Same height } \\
\text { with different } \\
\text { setups }\end{array}$} & \multirow{3}{*}{$\begin{array}{c}1.5 \mathrm{~m}+1 \mathrm{~m} \\
+1 \mathrm{~m}\end{array}$} & $\mathrm{~A}$ & 792.37 & 623.89 & 0.787 & & \\
\hline & & $\mathrm{B}$ & 981.69 & 754.38 & 0.768 & & \\
\hline & & $\mathrm{C}$ & 857.12 & 760.78 & 0.888 & & \\
\hline & \multirow{2}{*}{\begin{tabular}{|c|}
$\begin{array}{c}1.5 \mathrm{~m}+0.5 \\
\mathrm{~m} \\
+1.5 \mathrm{~m}\end{array}$ \\
\end{tabular}} & $\mathrm{~A}$ & 842.32 & 468.08 & 0.556 & & \\
\hline & & B & 873.34 & 634.19 & 0.726 & & \\
\hline & \multirow{2}{*}{\begin{tabular}{|c|}
$1.5 \mathrm{~m}+1.5$ \\
$\mathrm{~m}$ \\
$+0.5 \mathrm{~m}$
\end{tabular}} & $\mathrm{~A}$ & 874.54 & 380.58 & 0.435 & & \\
\hline & & B & 925.19 & 668.78 & 0.723 & & \\
\hline \multirow{2}{*}{$\begin{array}{l}\text { Same height } \\
\text { with different } \\
\text { number of } \\
\text { stories }\end{array}$} & \multirow[b]{2}{*}{$\begin{array}{c}\text { 3-story } \\
1.1 \mathrm{~m}\end{array}$} & $\mathrm{~A}$ & 1120.25 & 926.71 & 0.827 & & \\
\hline & & B & 1077.19 & 749.09 & 0.695 & & \\
\hline \multicolumn{8}{|c|}{$\begin{array}{l}\text { Notes: } \\
\text { Average value: } \bar{x}=\sum_{\mathrm{i}=1}^{\mathrm{n}} \mathrm{x}_{\mathrm{i}} / n ; \text { Standard deviation: } \quad \sigma=\sqrt{\frac{\sum(x-\bar{x})^{2}}{(n-1)}}\end{array}$} \\
\hline
\end{tabular}

Table 2 shows that the average of all strength reduction factors $(\mu)$ is 0.739 , and the standard deviation $(\sigma)$ is 0.111 . Figure 24 is the scatter plot from the average value plus or minus one standard deviation $(\mu \pm \sigma)$ to plus or minus three standard deviations $(\mu \pm 3 \sigma)$. 


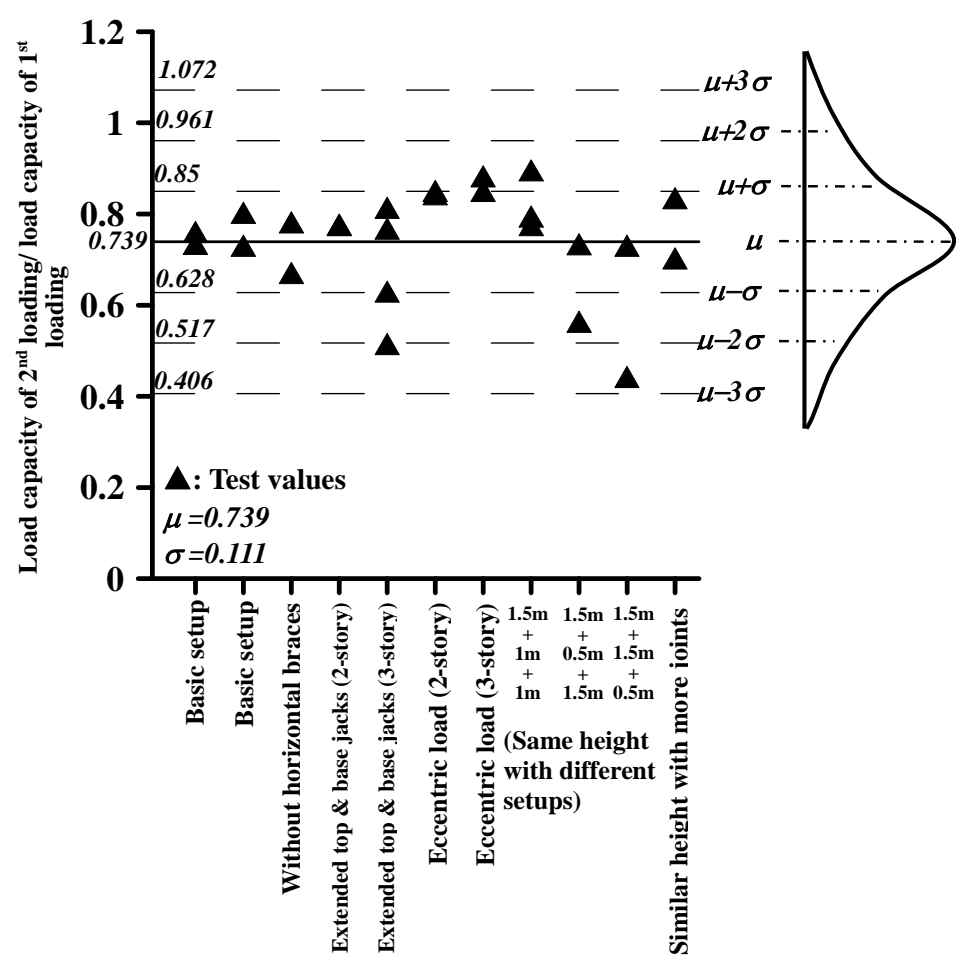

Figure 24. Scatter Plot of Average Strength Reduction Factors $(\phi)$ of Reusable Independent Heavy-duty Scaffolds based on $\mu \pm \sigma$ to $\mu \pm 3 \sigma$

Figure 24 shows that most of the strength reduction factors $(\phi)$ are located in the area of the average value plus or minus two standard deviations $(\mu \pm 2 \sigma)$ with the exception of only one test (same height with $1.5 \mathrm{~m}+1.5 \mathrm{~m}+0.5 \mathrm{~m}$ triangle-type scaffold units). During the first loading, the specimen was overloaded and unloaded too late, so it was too seriously damaged to serve as "reusable materials". This value may consider to be deleted.

Additionally, engineers may perform independent heavy-duty scaffold structural design at construction sites by referring to the strength reduction factors of reusable scaffolds shown in Figure 24 based on safety requirements. The strength reduction factor $(\phi)$ of reusable scaffolds with one standard deviation is $0.628(=\mu-\sigma=0.739-0.111)$. The reduction factor $(\phi)$ of reusable scaffolds with two standard deviations is $0.517(=\mu-2 \sigma=0.739-2 \times 0.111)$. The strength reduction factor $(\phi)$ of reusable scaffolds with three standard deviations is $0.406(=\mu-3 \sigma=0.739-3 \times 0.111)$. In this study, the strength reduction factor $(\phi)$ based on two standard deviations is appropriate for the structural design of independent heavy-duty scaffolds used in constructions.

\subsection{Comprehensive Comparisons}

Figure 25 compares the load capacities of all the independent heavy-duty scaffolds tested in this study. Figure 25 shows that the load capacity of three-story independent heavy-duty scaffolds does not significantly differ from that of two-story independent heavy-duty scaffolds. Situations of double eccentric loading $L / 3$ and rustiness scaffolds reduce the most load capacity of independent heavy-duty scaffolds. If the heights are similar, independent heavy-duty scaffolds assembled in the three different setups with the same number of joints have similar load capacities. The load capacity of three-story independent heavy-duty scaffolds assembled with $110 \mathrm{~cm}$ triangle-type scaffold units is higher than that of the two-story basic setup. 


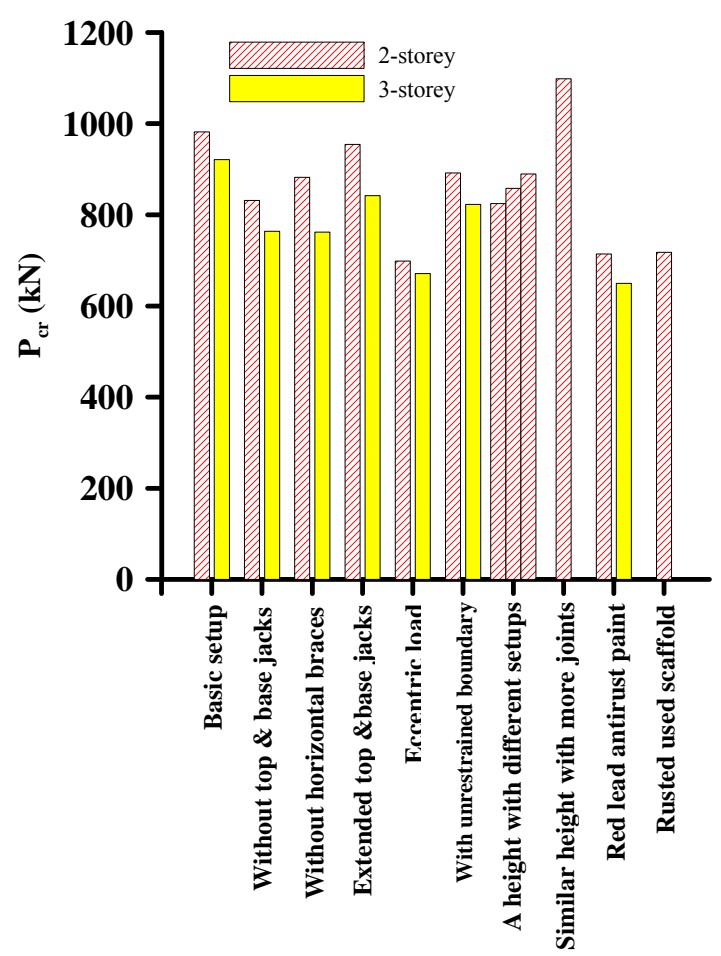

Figure 25. Comparisons of Load Capacities of Various Independent Heavy-duty Scaffold Setups

Figures 26 and 27 show the load capacities of various setups of two-story and three-story independent heavy-duty scaffolds comparing with those of the two-story and three-story basic setups respectively. Based on the load capacities of the two-story and three-story basic setups, the percentage of the load capacities of various setups of independent heavy-duty scaffolds to those of two- and three-story basic setups can be obtained.

The load capacities of two-story and three-story aging independent heavy-duty scaffolds treated with red lead antirust paint are $73 \%$ and $71 \%$, respectively, of the capacities of their basic setup counterparts. The load capacity of two-story reusable independent heavy-duty scaffolds assembled with rusted surfaces is $73 \%$ of that of the basic setup counterpart. The test results are consistent with the average strength reduction factor of load capacities of reusable independent heavy-duty scaffolds 0.739 (see Table 2 and Figure 24). These results show that the reduced load capacities of aging independent heavy-duty scaffolds treated with red lead antirust paint or have rusted surfaces are similar to the average strength reduction factor $\left(\phi_{\mu}\right)$ observed in the simulation of lower strength bounds of reusable scaffolds.

As shown by the test results, the second loading method used in this study to simulate the lower strength bounds of reusable scaffolds has a good practical value. Based on the average strength reduction factor $\left(\phi_{\mu}\right)$ of simulated lower strength bounds of reusable scaffolds, designers can choose proper strength reduction factors for reusable scaffolds based on safety requirements to perform structural design for independent heavy-duty scaffolds. 


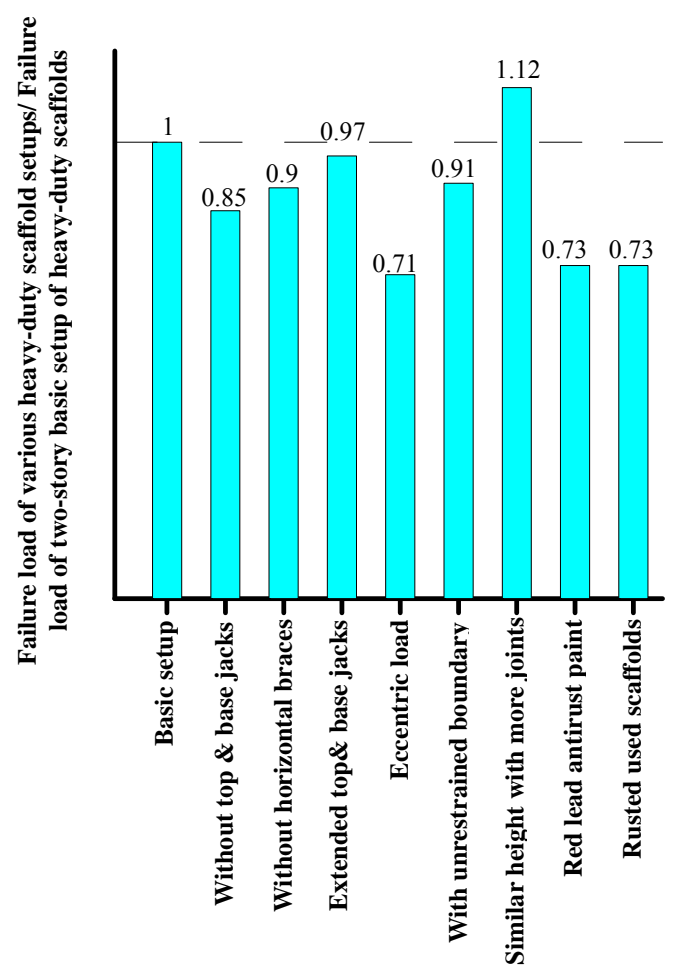

Figure 26. Comparisons of Load Capacities between Various

Two-story Independent Heavy-duty Scaffold Setups and Two-story Basic Setup

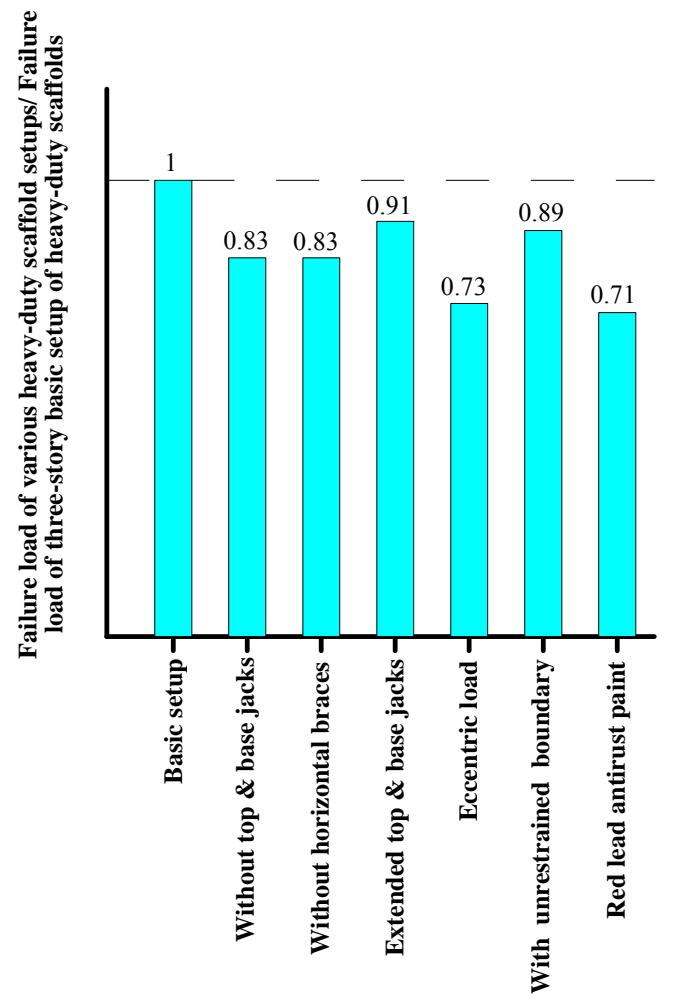

Figure 27. Comparisons of Load Capacities between Various Three-story Independent Heavy-duty Scaffold Setups and Three-story Basic Setup 


\section{CONCLUSIONS}

This study investigated the stability of various setups of independent heavy-duty scaffolds commonly used on construction sites in Taiwan. The following conclusions and suggestions are based on the results of experiments performed in two-story and three-story scaffolds:

1. The load capacity of three-story independent heavy-duty scaffolds is not significantly lower than that of two-story independent heavy-duty scaffolds. The top and base screw jacks provide extra bending moment stiffness for independent heavy-duty scaffolds. Thus, seriously deformed top and base screw jacks are not safe for use in independent heavy-duty scaffolds. Since horizontal braces can enhance the load capacity of independent heavy-duty scaffolds and the stable during lifting and moving scaffolds, they cannot be neglected when assembling independent heavy-duty scaffolds. Extension of the top and base screw jacks does not substantially affect the load capacity of independent heavy-duty scaffolds. Thus, the height of top and base screw jacks can be adjusted to suit the internal clearances and landforms of the building. For a given height, independent heavy-duty scaffolds are assembled with different sizes of triangle-type scaffold units, as long as the number of joints is the same, the load capacities are similar. In addition, test results show that all vertical members of scaffolds can take most total vertical loads, but the tube forces of horizontal ledgers are unobvious.

2. This study revealed that the load capacity of independent heavy-duty scaffolds with such conditions as double eccentric loading L/3 and aging scaffolds treated with red lead antirust paint or rusted surfaces is decreased by approximately 30\%. These strength affecting factors should be taken into account when engineers perform structural design for independent heavy-duty scaffolds.

3. The average of strength reduction factors $(\mu)$ of simulated lower strength bounds of reusable scaffolds is 0.739 and the standard deviation $(\sigma)$ is 0.111 . The strength reduction factors $(\phi)$ of reusable scaffolds minus one, two and three standard deviations are $0.628,0.517$ and 0.406 respectively. When performing structural design for independent heavy-duty scaffolds, engineers can choose proper strength reduction factors for reusable scaffolds based on their safety requirements. The reduction in load capacity of reusable independent heavy-duty scaffolds treated with red lead antirust paint or rusted surfaces is similar to the average reduction factor (0.739) for lower strength bounds of reusable scaffolds, indicating that the second loading method used in this study to simulate the lower limit value of the strength of reusable scaffolds has pretty good reliability and usability.

4. The boundary lateral displacement tests revealed the difficulty of simulating lateral displacement of the boundary in the testing laboratory. The load capacity of three-story independent heavy-duty scaffolds assembled with $110 \mathrm{~cm}$ triangle-type scaffold units is higher than that of the two-story basic setup with $150 \mathrm{~cm}$ triangle-type scaffold units. This implies that $110 \mathrm{~cm}$ triangle-type scaffold units provide a stronger scaffolding structure compared to $150 \mathrm{~cm}$ triangle-type scaffold units.

\section{ACKNOWLEDGEMENT}

The authors would like to thank the Ministry of Science and Technology, for funding this study (MOST 106-2221-E-224-016), Hua Construction Ltd. for sponsoring independent heavy-duty scaffolds as test materials, and Mr. Jian, Ming-zhi for assistance with experiments. 


\section{REFERENCES}

[1] Zhang, H., Chandrangsu, T. and Rasmussen, K.J.R., "Probabilistic study of the strength of steel scaffold systems", Structural Safety, 2010, Vol. 32, pp.393-401.

[2] Weesner, L.B. and Jones, H.L., "Experimental and Analytical Capacity of Frame Scaffolding ”, Engineering Structures, 2001, Vol. 23, No. 6, pp.592-599.

[3] Yu, W.K. and Chung K.F., "Prediction on Load Carrying Capacities of Multi-storey Door-type Modular Steel Scaffolds", Steel and Composite Structures, 2004, Vol. 4, No. 6, pp.471-487.

[4] Yu, W.K., Chung, K.F. and Chan, S.L., "Structural Instability of Multi-storey Door-type Modular Steel Scaffolds”, Engineering Structures, 2004, Vol. 26, pp.867-881.

[5] Peng, J.L., Pan, A.D., Rosowsky, D.V., Chen, W.F., Yen, T., and Chan, S.L., "High Clearance Scaffold Systems during Construction - I. Structural Modelling and Modes of Failure", Engineering Structures, 1996, Vol. 18, No. 3, pp.247-257.

[6] Peng, J.L., Rosowsky, D.V., Pan, A.D., Chen, W.F., Chan, S.L., and Yen, T., "High Clearance Scaffold Systems during Construction - II. Structural Analysis and Development of Design Guidelines", Engineering Structures, 1996, Vol. 18, No. 3, pp. 258-267.

[7] Peng, J.L., Ho, C.M., Lin, C.C., and Chen, W.F., "Load-Carrying Capacity of Single-Row Steel Scaffolds with Various Setups", Journal of Advanced Steel Construction, 2015, Vol. 11, No. 2, pp.185 210.

[8] Peng, J.L., Wang, P.L., Huang, Y.H., and Tsai, T.C., "Experimental Studies of Load Capacities of Double-Layer Shoring Systems", Journal of Advanced Steel Construction, 2010, Vol. 6, No. 2, pp.698-721.

[9] Peng, J.L., Yen, T., Kuo, C.C., and Chan, S.L., "Analytical and Experimental Bearing Capacities of System Scaffolds", Journal of Zhejiang University SCIENCE A, 2009, Vol. 10, No. 1, pp.82-92.

[10] Liu, H., Zhao, Q., Wang, X., Zhou, T., Wang, D., Liu, J., and Chen, Z., "Experimental and Analytical Studies on the Stability of Structural Steel Tube and Couple Scaffolds without X-bracing”, Engineering Structures, 2010, Vol. 32, No. 4, pp.1003-1015.

[11] Peng, J.L., Ho, C.M., Chen, C.Y., and Yang, Y.B., "Experimental Study on Load Capacities of Isolated Heavy-Duty Scaffolds Used in Construction", Journal of Advanced Steel Construction, 2014, Vol. 10, No. 3, pp.248 273. 